\title{
Substituição do Grão de Milho pelo Milheto (Pennisetum americanum) na Dieta de Vacas Holandesas em Lactação
}

\section{Cláudio Vaz Di Mambro Ribeiro1, Alexandre Vaz Pires², José Manuel Correia de Simas², Flávio Augusto Portela Santos ${ }^{2}$, Ivanete Susin², Reinaldo Cunha de Oliveira Junior ${ }^{1}$}

\begin{abstract}
RESUMO - Com o objetivo de se utilizar um substituto de menor custo para o milho, avaliou-se o efeito da substituição do grão de milho pelo grão de milheto, com base no teor de amido dos mesmos, sobre o desempenho e parâmetros ruminais de quatro vacas holandesas, com 90 dias de lactação em média (70 a 110 dias), em um delineamento em Quadrado Latino Incompleto 5x4. Os animais foram alimentados com dietas contendo $52,4 \%$ concentrado: $48,6 \%$ silagem de milho na matéria seca. Os tratamentos consistiram das seguintes proporções de amido de milho e milheto: 100:0; 75:25; 50:50; 25:75; 0:100, respectivamente. Não foram encontradas diferenças no consumo de matéria seca, produção de leite $(24,6 \mathrm{~kg} / \mathrm{d})$ e de leite corrigido para 3,5\% de gordura $(23,8 \mathrm{~kg} / \mathrm{d})$. O teor e produção de gordura e a produção de proteína do leite também não foram diferentes entre os tratamentos. Observou-se efeito quártico sobre o teor de proteína do leite, quando se elevou o teor de amido do milheto de 25 para 100\%. Não houve diferença entre os tratamentos na concentração de acetato, propionato, ácidos graxos voláteis totais e pH ruminal, ocorrendo efeito linear negativo na concentração de $\mathrm{N}-\mathrm{NH}_{3}$ com o aumento do teor de milheto. A substituição de milho por milheto não alterou o desempenho de vacas holandesas em lactação.
\end{abstract}

Palavras-chave: Pennisetum americanum, amido, AGV

\section{Substitution of Corn Grain by Pearl Millet in the Diet of Dairy Holstein Cows}

ABSTRACT - Animal production and and ruminal parameters were analyzed to evaluate the substitution of corn by pearl millet. Four lactating cannulated Holstein cows were used in a incomplete 5X4 Latin Square design. Cows were fed a 48.6\% corn silage diet (dry matter basis). Treatments consisted of substitution of corn stacrh by pearl millet in five different proportions: 100:0, 75:25, 50:50, 25:75 and 0:100. All grain substitutions were estimated in the starch content basis. There was no effect of grain source on dry matter intake, milk yield and milk fat percent. However, there was a quartic effect on milk protein content, as pearl millet grain increased. There was no treatment effect on ruminal $\mathrm{pH}$, acetate, propionate, butyrate and total volatile fatty acids concentration. There was a linear effect on ruminal $\mathrm{N}-\mathrm{NH}_{3}$ concentration, when pearl millet was increased. Pearl millet substitution for corn does not seem to affect performance of lactating Holstein cows.

Key Words: Pennisetum americanum, starch, VFA

\section{Introdução}

O milheto (Pennisetum americanum) é uma forrageira de ciclo anual que vem ocupando espaço na alimentação de gado de corte, seja em pastejo ou sob a forma de grãos como fonte alternativa de energia, constituindo-se um importante cereal na Índia, África, Arábia e Paquistão (Fancher et al., 1987; Landry \& Delhaye, 1995).

Estima-se que vinte e seis milhões de hectares são plantados na África e Ásia, regiões semi-áridas onde essa espécie está adaptada (Andrews \& Kumar, 1992). No Brasil, a região Centro-Oeste se destaca na utilização desse grão, uma vez que suas características agronômicas e nutritivas o qualificam como possível substituto energético na alimentação animal.

$\mathrm{O}$ aumento da degradabilidade do amido no rúmen tem se mostrado útil, não só por maximizar a capacidade fermentativa do rúmen, aumentando a síntese de proteína microbiana e produção de $\mathrm{AGV}$, mas também por promover economia no metabolismo energético e protéico do hospedeiro (Huntington, 1994). O local e a extensão da fermentação ruminal do amido são dados importantes para o melhor aproveitamento dos grãos. Freeman (dados não publicados), citado por Burton et

\footnotetext{
${ }^{1}$ Alunos de pós-graduação do Depto. de Zootecnia Ruminantes, ESALQ/USP - Av. Pádua Dias , 11 - Caixa Postal 9. CEP:13418900 Piracicaba, SP (alvpires@esalq.usp.br).

2 Professores, PhD - Depto. de Zootecnia Ruminantes, ESALQ/USP - Av. Pádua Dias , 11 - Caixa Postal 9. CEP: 13418900 Piracicaba, SP.
} 
al. (1972), encontrou 72 e 61,5\% de amido para os grãos de milho e milheto, mas não avaliou o padrão de fermentação ruminal do amido dos grãos.

$\mathrm{O}$ efeito do consumo do grão de milheto no desempenho de vacas holandesas ainda não foi estudado. Esse conhecimento pode ser valioso na adoção de uma estratégia de substituição de fontes de amido, principalmente em regiões de baixa pluviosidade, podendo ainda diminuir o custo do concentrado.

Objetivou-se, neste trabalho, avaliar o consumo de matérias seca, composição do leite e parâmetros ruminais de vacas de leite alimentadas com milheto como substituto do milho, para o conhecimento de limitações e uso deste grão.

\section{Material e Métodos}

Foram utilizadas quatro vacas holandesas Preta e Branca, multíparas, em média com 90 dias pós-parto (70 a 110 dias), dotadas de cânulas ruminais, consumindo $19 \mathrm{~kg}$ de matéria seca por dia. Os animais foram everminados e receberam doses de vitamina $\mathrm{A}, \mathrm{D}$ e $\mathrm{E}$ antes de se iniciar os trabalhos.

Todos os períodos experimentais foram conduzidos nas instalações de Pesquisa em Nutrição Animal do Departamento de Produção Animal, setor de Ruminantes da ESALQ/USP, em Piracicaba, SP. Os animais foram alojados em galpão parcialmente aberto equipado com ventiladores, mantidos em baias $(2,5 \times 1,10 \mathrm{~m})$ tipo "tie stall", providas de comedouros individuais e bebedouros automáticos a cada duas baias, além de um tapete de borracha colocado no piso. Os animais eram soltos 1 hora por dia, para se exercitarem, em um piquete ao lado do galpão.

A fase experimental teve duração de 70 dias, divididos em cinco períodos de 14 dias. Os primeiros 10 dias de cada período foram utilizados para adaptação dos animais aos tratamentos e os quatro dias restantes, para as coletas de fluido ruminal, sangue, leite e amostras e das sobras do alimento.

As dietas (Tabela 1) foram constituídas de silagem de milho como volumoso (48,6\% da MS). Avaliou-se a substituição do grão de milho pelo grão de milheto, sendo a porcentagem de substituição relacionada com o teor de amido desses grãos (Tabelas 1 e 2). Os tratamentos foram: 1) $100 \%$ de amido do milho; 2) $75 \%$ de amido de milho e $25 \%$ de milheto; 3) $50 \%$ de amido de milho e $50 \%$ de milheto; 4) $25 \%$ de amido de milho e $75 \%$ de milheto; 5) $100 \%$ de amido de milheto. Foi determinado, previamente, o teor de amido do milho e milheto para a obtenção dos tratamentos (Tabela 3). Na dieta com 50\% de inclusão de amido de milheto, por exemplo, a quantidade de amido proveniente do milheto foi igual à quantidade de amido oriunda do milho. Como o milho possui maior teor desse nutriente $(71,7 \%$ vs $62 \%$ do milheto), sua quantidade, em gramas, é menor (Tabelas 2 e 3 ).

O alimento concentrado foi misturado previamente para cada período em misturador horizontal (marca Lucato, capacidade $500 \mathrm{~kg}$ ). Por ocasião do fornecimento da alimentação, as quantidades de volumoso e concentrado foram pesadas separadamente para posterior mistura no cocho, visando a obtenção da ração completa de cada animal. O fornecimento da ração foi realizado duas vezes ao dia $(6$ e 18 h) ad libitum, simultaneamente ao horário de ordenha, permitindo sobra de 5 a $10 \%$ do oferecido, para evitar limitação de consumo. As amostras de alimento oferecido e recusado foram coletadas diariamente durante $o$ período de avaliação (quatro dias) para posteriores análises laboratoriais.

Os dados de consumo de matéria seca (MS) por animal/dia foram obtidos pela diferença entre quantidade de MS fornecida e sobra.

$\mathrm{O}$ alimento fornecido e as sobras foram pesados e amostrados $(250 \mathrm{~g})$ diariamente durante os quatro dias de coleta de cada período e compostas por vaca por período, perfazendo um total de aproximadamente $2,0 \mathrm{~kg} / \mathrm{vaca}$.período ${ }^{-1}$. As amostras foram conservadas congeladas a $-10^{\circ} \mathrm{C}$. Após o término do período, foram descongeladas e secas em estufas de ventilação forçada $\left(55-60^{\circ} \mathrm{C}\right)$, por 72 horas, para determinação de matéria seca e, posteriormente, processadas em moinho tipo Willey, provido de peneira de $1 \mathrm{~mm}$. Foram analisadas para matéria seca $\left(105^{\circ} \mathrm{C}\right.$ durante $\left.5 \mathrm{~h}\right)$, matéria orgânica (MO), proteína bruta (PB) e extrato etéreo (EE) de acordo com o AOAC (1990), amido de acordo com Poore et al. (1989), e fibra em detergente neutro (FDN) e fibra em detergente ácido (FDA) de acordo com Van Soest et al. (1991), utilizando-se o aparelho ANKOM $^{200}$ da Ankom Technology Corporation.

As amostras de conteúdo ruminal - coletadas imediatamente antes e 2, 4, 6, 8 e 10 horas após a alimentação da manhã do primeiro dia de coleta de cada período - foram obtidas de quatro pontos distintos do rúmen, filtradas em quatro camadas de tecido de algodão (fraldas), obtendo-se 
aproximadamente, $300 \mathrm{~mL}$ de filtrado (fluido ruminal).

$\mathrm{O} \mathrm{pH}$ ruminal foi determinado imediatamente por meio de leitura direta em medidor digital de $\mathrm{pH}$ da Digimed, modelo DM-20. Duas alíquotas de $50 \mathrm{~mL}$ foram acondicionadas em frascos plásticos e congeladas a $-10^{\circ} \mathrm{C}$ para posterior análise da concentração de nitrogênio na forma de amônia $\left(\mathrm{N}-\mathrm{NH}_{3}\right)$ e ácidos graxos voláteis (AGV).

Para determinação do $\mathrm{N}-\mathrm{NH}_{3}$, as amostras foram descongeladas e centrifugadas a $11.000 \mathrm{~g} \mathrm{a} 4^{\circ} \mathrm{C}$, durante 20 minutos, e uma alíquota de $4 \mathrm{~mL}$ foi transferida para um tubo de vidro, para posterior análise de acordo com o método colorimétrico descrito por Chaney \& Marbach (1962), adaptado para ser usado em placas de microtítulo e leitura em aparelho do tipo Elisa Reader (absorbância de 550 nanômetros).

Para determinação de AGV, as amostras foram descongeladas e centrifugadas, conforme descrito acima, e analisadas de acordo com Suplenco Incorporation (1975), utilizando um cromatógrafo líquido-gasoso (CLG) Hewlett Packard 5890, Series II (Hewlett Packard Company, Avondale, PA)

\begin{tabular}{|c|c|c|c|c|c|}
\hline \multirow{3}{*}{$\begin{array}{l}\text { Ingredientes } \\
\text { Ingredient }\end{array}$} & \multicolumn{5}{|c|}{$\begin{array}{l}\text { Tratamentos } \\
\text { Treatments }\end{array}$} \\
\hline & \multicolumn{5}{|c|}{$\begin{array}{l}\% \text { de inclusão de milheto } \\
\quad \% \text { of pearl millet }\end{array}$} \\
\hline & $0 \%$ & $25 \%$ & $50 \%$ & $75 \%$ & $100 \%$ \\
\hline $\begin{array}{l}\text { Silagem de milho } \\
\text { Corn silage }\end{array}$ & 48,60 & 48,60 & 48,60 & 48,60 & 48,60 \\
\hline $\begin{array}{l}\text { Farelo de soja } \\
\text { Soybean meal }\end{array}$ & 19,07 & 17,93 & 16,20 & 14,69 & 12,76 \\
\hline $\begin{array}{l}\text { Milho } \\
\text { Corn }\end{array}$ & 29,01 & 21,74 & 14,58 & 7,35 & - \\
\hline $\begin{array}{l}\text { Milheto } \\
\text { Pearl millet }\end{array}$ & - & 8,37 & 17,28 & 26,01 & 35,22 \\
\hline $\begin{array}{l}\text { Uréia } \\
\text { Urea }\end{array}$ & 0,81 & 0,82 & 0,81 & 0,82 & 0,83 \\
\hline $\begin{array}{l}\text { Premix }^{2} \\
\text { Premix }\end{array}$ & 1,90 & 1,93 & 1,92 & 1,94 & 2,00 \\
\hline $\begin{array}{l}\text { Bic. de sódio } \\
\text { Sodium bicarbonate } \\
\text { Composição bromatológica }\end{array}$ & 0,81 & 0,80 & 0,80 & 0,80 & 0,80 \\
\hline $\begin{array}{l}\text { Chemical composition } \\
\text { Matéria orgânica } \\
\text { Dry matter }\end{array}$ & 93,55 & 93,51 & 93,46 & 93,61 & 93,83 \\
\hline $\begin{array}{l}\text { Proteína bruta } \\
\text { Crude protein }\end{array}$ & 18,64 & 18,43 & 18,02 & 17,93 & 17,39 \\
\hline $\begin{array}{l}\text { Amido } \\
\text { Starch }\end{array}$ & 35,45 & 35,43 & 35,72 & 35,88 & 35,45 \\
\hline $\begin{array}{l}\text { Extrato etéreo } \\
\text { Ether extract }\end{array}$ & 3,12 & 3,29 & 3,35 & 3,26 & 3,42 \\
\hline $\begin{array}{l}\text { Fibra em detergente neutro } \\
\text { Neutral detergent fiber }\end{array}$ & 29,35 & 29,33 & 29,69 & 29,80 & 30,21 \\
\hline $\begin{array}{l}\text { Fibra em detergente ácido } \\
\text { Acid detergent fiber }\end{array}$ & 15,52 & 15,37 & 15,50 & 15,51 & 15,57 \\
\hline $\mathrm{EL}_{\mathrm{L}}^{3}, \mathrm{Mcal} / \mathrm{kg}$ & 1,58 & 1,58 & 1,58 & 1,59 & 1,58 \\
\hline
\end{tabular}


equipado com HP Integrador (Hewlett- Packard Company, Avondale, PA ). Como padrão interno, utilizou-se o ácido 2-etilbutírico, adicionando-se 100 $\mu \mathrm{L}$ do padrão para $800 \mu \mathrm{L}$ da mistura fluido ruminal e $200 \mu \mathrm{L}$ de ácido metafosfórico nos tubos HP 5890 para leitura em cromatógrafo. $\mathrm{O}$ nitrogênio foi utilizado como o gás de arraste e a temperatura do injetor, detector e coluna foram 150,190 e $115^{\circ} \mathrm{C}$, respectivamente.

As vacas foram ordenhadas duas vezes ao dia e a produção de leite registrada diariamente. Amostras de leite também foram colhidas duas vezes ao dia (manhã e tarde) durante os quatro dias de coleta de cada período, compostas por dia e preservadas em 2-bromo-2-nitropropano-1-3-diol sob refrigeração $\left(6^{\circ} \mathrm{C}\right)$ por um dia para análise de proteína e gordura utilizando o Infrared Analyser Bentley 2000.

O delineamento estatístico utilizado foi o quadrado latino incompleto $5 \times 4$ (cinco períodos $\mathrm{x}$ quatro animais). As diferenças estatísticas dos parâmetros foram determinadas utilizando-se o seguinte modelo matemático:

$$
\mathrm{Y}_{\mathrm{ijk}}=\mu+\mathrm{T}_{\mathrm{i}}+\mathrm{p}_{\mathrm{j}}+\mathrm{a}_{\mathrm{k}}+\mathrm{e}_{\mathrm{ijk}}
$$

em que $\boldsymbol{\mu}=$ média geral; $\mathbf{T}_{\mathbf{i}}=$ efeito fixo da dieta; $\mathbf{p}_{\mathbf{j}}=$ efeito aleatório de período; $\mathbf{a}_{\mathbf{k}}=$ efeito aleatório de animal; $\mathbf{e}_{\mathbf{i j k}}=$ erro experimental.

Os dados coletados foram analisados por intermédio

Tabela 2 - Quantidade de amido proveniente dos grãos de cereais

Table 2 - Amout of starch deriving from cereal grains

\begin{tabular}{lccccc}
\hline $\begin{array}{l}\text { Fontes } \\
\text { de amido }\end{array}$ & \multicolumn{5}{c}{$\begin{array}{c}\text { Tratamentos } \\
\text { Treatments }\end{array}$} \\
\cline { 2 - 6 } $\begin{array}{l}\text { Sources } \\
\text { of starch }\end{array}$ & \multicolumn{5}{c}{$\begin{array}{c}\text { \% de inclusão de milheto } \\
\text { \% of pearl millet }\end{array}$} \\
\cline { 2 - 6 } & $0 \%$ & $25 \%$ & $50 \%$ & $75 \%$ & $100 \%$ \\
\hline $\begin{array}{l}\text { Milheto, \% } \\
\text { Pearl millet } \\
\text { Milho, \% }\end{array}$ & - & 5,19 & 10,72 & 16,13 & 21,84 \\
$\begin{array}{l}\text { Corn } \\
\text { Total }\end{array}$ & 20,80 & 15,59 & 10,46 & 5,27 & - \\
Total $^{2}$ & 20,80 & 20,78 & 21,18 & 21,4 & 21,84 \\
\hline
\end{tabular}

${ }_{1}^{1}$ Porcentagem de inclusão do amido do milheto em relação ao amido do milho ( Percentage of pearl millet stach added in relation to corn starch).

2 Amido proveniente dos grãos de cereais (Starch deriving from cereal grains).

R. Bras. Zootec., v.33, n.5, p.1351-1359, 2004 o comando PROC MIXED do programa estatístico SAS (SAS, 1991). Este procedimento define as variáveis fixas e aleatórias do modelo, utiliza o método de máxima verossimilhança restrita para estimar os componentes de variância e é apropriado para dados desbalanceados (Perri \& Iemma, 1999). Foi considerado 5\% como nível de significância. Contrastes ortogonais foram utilizados para definir os efeitos linear (L), quadrático $(\mathrm{Q})$, cúbico $(\mathrm{C})$ e quártico $(\mathrm{Qt})$. Para as variáveis $\mathrm{pH}, \mathrm{AGV}$ e $\mathrm{N}-\mathrm{NH}_{3}$, utilizou-se o comando PROC MIXED para a análise de medidas repetidas no tempo. Antes, porém, foi selecionada uma matriz de estrutura de variâncias que melhor representasse os parâmetros avaliados. As diferenças estatísticas dos parâmetros no tempo foram determinadas utilizando-se o seguinte modelo matemático:

$$
\mathrm{Y}_{\mathrm{ijkl}}=\mu+\mathrm{D}_{\mathrm{i}}+\mathrm{p}_{\mathrm{j}}+\mathrm{a}_{\mathrm{k}}+\mathrm{e}_{\mathrm{ijk}}+\mathrm{T}_{1}+(\mathrm{T} * \mathrm{D})_{\mathrm{il}}+\mathrm{k}_{\mathrm{ijkl}}
$$

em que $\boldsymbol{\mu}=$ média geral; $\mathbf{D}_{\mathbf{i}}=$ efeito fixo da dieta; $\mathbf{p}_{\mathbf{j}}=$ efeito aleatório do período; $\mathbf{a}_{\mathbf{k}}=$ efeito aleatório do animal; $\mathbf{e}_{\mathbf{i j k}}=$ erro experimental da parcela; $\mathbf{T}_{\mathbf{j}}=$ efeito fixo do tempo; $\left(\mathbf{T}^{*} \mathbf{D}\right)_{\mathbf{i l}}=$ interação tempo*tratamento; $\mathbf{k}_{\mathbf{i j k l}}=$ erro experimental $\mathrm{da}$ subparcela.

Todas as médias apresentadas em textos e tabelas foram obtidas pelo comando LSMEANS do SAS (1991).

Tabela 3 - Análise bromatológica do milho e milheto (\% MS)

Table 3 - Chemical composition of corn and pearl millet (\%DM)

Composição bromatológica $^{1} \quad$ Milho $\quad$ Milheto

Chemical composition Corn Pearl millet

\begin{tabular}{lll}
\hline Proteína bruta & 8,5 & 15,2
\end{tabular}

Crude protein

$\begin{array}{lll}\text { Fibra em detergente neutro } & 18,3 & 18,7\end{array}$

Neutral detergent fiber

Fibra em detergente ácido $\quad 2,1 \quad 6,5$

Acid detergente fiber

Matéria Mineral $\quad 1,1 \quad 2,3$

Minerals matter

Amido

$71,7 \quad 62,0$

Starch 


\section{Resultados e Discussão}

Os valores da composição bromatológica dos grãos (Tabela 2) estão de acordo com os valores do NRC (1988). O milheto avaliado (Tabela 3) apresentou menor concentração de amido em relação ao milho (62 vs $72 \%$ ) e maiores concentrações de proteína $(15,8 \%)$ e extrato etéreo $(5,4 \%)$. Os teores dos nutrientes encontrados para o milheto estão de acordo com valores de Freeman (dados não publicados) citado por Burton et al. (1972), e o teor de amido do grão de milho (72\%) está próximo dos valores citados por Huntington (1997) e Joy et al. (1997). As dietas com maiores concentrações de milheto continham menor quantidade de farelo de soja, para que o nível protéico entre os tratamentos permanecesse constante.

Não houve efeito $(\mathrm{P}>0,05)$ da fonte de amido sobre o consumo de matéria seca (CMS) e matéria orgânica (MO), indicando que a aceitabilidade do milheto foi igual a do milho (Tabela 4).

Em experimento com cabras, Gelaye et al. (1997) observaram que dietas com grãos de milheto não foram bem aceitas pelos animais em crescimento e, segundo os autores, seria resultado da diminuição na palatabilidade da mesma, necessitando-se melhor adaptação dos animais a esse grão.

Terrill et al. (1998) obtiveram maior consumo de MS em dietas de cabras (40\% de grãos), quando o milho foi totalmente substituído por milheto, mas, segundo os autores, o aumento de $28 \%$ na ingestão foi para que os animais atingissem seus requerimentos energéticos.

Os dados sugerem que não há diferença em palatabilidade ou distúrbios pós-ingestivos que pudessem causar uma diminuição no CMS, proporcionando igual aceitação entre os animais do grão de milheto e milho. Também não foram encontradas diferenças $(\mathrm{P}>0,05)$ no consumo de nutrientes entre os tratamentos (Tabela 4), provavelmente em razão de as dietas terem percentagens muito próximas dos nutrientes, proporcionando um padrão de consumo similar ao CMS. Entretanto, o consumo de nitrogênio foi inversamente proporcional ao aumento de milheto na dieta (Tabela 4), em função da pequena diminuição da concentração protéica da dieta, à medida que se aumentou o teor de milheto (Tabela 1). Conseqüentemente, observou-se efeito linear $(\mathrm{P}<0,05)$ entre a inclusão de milheto na dieta e a eficiência (Efic.) de conversão da proteína consumida pela proteína no leite (Tabela 5).

A produção de leite e leite corrigido para gordura (Tabela 5) não foram afetados $(\mathrm{P}>0,05)$ pela fonte de amido. Também não houve diferença $(\mathrm{P}>0,05)$ para a produção de proteína no leite e percentagem e quantidade de gordura entre os tratamentos, porém

Tabela 4 - Substituição do milho por milheto sobre o consumo de MS e nutrientes Table 4 - Substitution of corn by pearl millet on nutrients and DM intake

\begin{tabular}{|c|c|c|c|c|c|c|c|c|c|c|}
\hline \multirow[t]{2}{*}{$\begin{array}{l}\text { Itens }{ }^{3} \\
\text { Items }\end{array}$} & \multicolumn{5}{|c|}{$\begin{array}{c}\text { Tratamentos }^{1} \\
\text { Treatments } \\
\end{array}$} & \multirow[b]{2}{*}{ EPM4 } & \multicolumn{4}{|c|}{$\begin{array}{c}\text { Efeito }^{2} \\
\text { Effect }\end{array}$} \\
\hline & $0 \%$ & $25 \%$ & $50 \%$ & $75 \%$ & $100 \%$ & & $\mathrm{~L}$ & $\mathrm{Q}$ & $\mathrm{C}$ & $\mathrm{Qt}$ \\
\hline $\begin{array}{l}\mathrm{MO}(\%) \\
O M\end{array}$ & 18,06 & 18,26 & 17,73 & 17,72 & 17,33 & 1,62 & 0,321 & 0,773 & 0,851 & 0,679 \\
\hline $\begin{array}{l}\text { Amido (\%) } \\
\text { Starch }\end{array}$ & 6,90 & 6,98 & 6,88 & 7,03 & 6,64 & 0,61 & 0,688 & 0,600 & 0,743 & 0,683 \\
\hline $\begin{array}{l}\mathrm{FDN}(\%) \\
N D F\end{array}$ & 5,41 & 5,48 & 5,33 & 5,27 & 5,26 & 0,56 & 0,450 & 0,929 & 0,704 & 0,869 \\
\hline $\begin{array}{l}\text { FDA }(\%) \\
A D F\end{array}$ & 2,82 & 2,85 & 2,75 & 2,69 & 2,68 & 0,29 & 0,231 & 0,940 & 0,604 & 0,894 \\
\hline $\begin{array}{l}\mathrm{EE}(\%) \\
E E\end{array}$ & 0,63 & 0,65 & 0,66 & 0,64 & 0,65 & 0,07 & 0,812 & 0,769 & 0,802 & 0,799 \\
\hline $\mathrm{N}(\%)$ & 0,57 & 0,58 & 0,55 & 0,54 & 0,52 & 0,05 & 0,048 & 0,584 & 0,750 & 0,534 \\
\hline
\end{tabular}

1 Porcentagem de inclusão do amido do milheto em relação ao amido do milho.

1 Percentage of pearl millet stach added in relation to corn starch.

2 Probabilidade de haver efeito $(P): L=$ Linear; $Q=$ quadrático; $C=$ Cúbico; $Q t$ quártico.

2 Probability of treatment effect: $L=$ linear; $Q=$ quadratic; $C=$ cubic; $Q t=$ quartic.

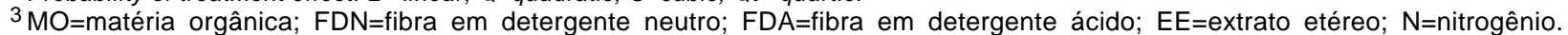

3 OM=organic matter; $N D F=$ neutral detergent fiber; $A D F=$ acid detergent fiber; $E E=$ ether extract.

4 Erro-padrão da média.

${ }^{4}$ Standard error of mean.

R. Bras. Zootec., v.33, n.5, p.1351-1359, 2004 
Tabela 5 - Inclusão de milheto sobre a produção e composição do leite Table 5 - Pearl millet on milk production and composition

\begin{tabular}{|c|c|c|c|c|c|c|c|c|c|c|}
\hline \multirow[t]{2}{*}{$\begin{array}{l}\text { Itens }{ }^{3} \\
\text { Items }\end{array}$} & \multicolumn{5}{|c|}{$\begin{array}{c}\text { Tratamentos } \\
\text { Treatments } \\
\end{array}$} & \multirow[b]{2}{*}{$\mathrm{EPM}^{4}$} & \multicolumn{4}{|c|}{$\begin{array}{c}\text { Efeito }^{2} \\
\text { Effect }\end{array}$} \\
\hline & $0 \%$ & $25 \%$ & $50 \%$ & $75 \%$ & $100 \%$ & & $\mathrm{~L}$ & Q & $\mathrm{C}$ & $\mathrm{Qt}$ \\
\hline $\begin{array}{l}\text { CMS } \\
D M I\end{array}$ & 19,28 & 19,53 & 18,97 & 18,89 & 18,52 & 1,73 & 0,310 & 0,758 & 0,800 & 0,705 \\
\hline $\begin{array}{l}\text { PL } \\
M Y\end{array}$ & 24,30 & 24,18 & 25,11 & 25,06 & 24,50 & 2,82 & 0,626 & 0,551 & 0,550 & 0,418 \\
\hline $\begin{array}{l}\text { PLC } \\
M Y C F\end{array}$ & 23,79 & 23,49 & 24,61 & 24,22 & 23,11 & 2,03 & 0,771 & 0,243 & 0,335 & 0,521 \\
\hline $\begin{array}{l}\text { Proteína } \\
\text { Protein }\end{array}$ & & & & & & & & & & \\
\hline $\begin{array}{l}(\mathrm{kg}) \\
(\%)\end{array}$ & $\begin{array}{l}0,73 \\
3,00\end{array}$ & $\begin{array}{l}0,74 \\
3,08\end{array}$ & $\begin{array}{l}0,75 \\
3,02\end{array}$ & $\begin{array}{l}0,76 \\
3,04\end{array}$ & $\begin{array}{l}0,72 \\
2,96\end{array}$ & $\begin{array}{l}0,08 \\
0,17\end{array}$ & $\begin{array}{l}0,849 \\
0,040\end{array}$ & $\begin{array}{l}0,353 \\
0,007\end{array}$ & $\begin{array}{l}0,520 \\
0,416\end{array}$ & $\begin{array}{l}0,790 \\
0,040\end{array}$ \\
\hline Gordura & & & & & & & & & & 0414 \\
\hline $\begin{array}{l}(\mathrm{kg}) \\
(\%)\end{array}$ & $\begin{array}{l}0,82 \\
3,39\end{array}$ & $\begin{array}{l}0,80 \\
3,41\end{array}$ & $\begin{array}{l}0,85 \\
3,52\end{array}$ & $\begin{array}{l}0,82 \\
3,34\end{array}$ & $\begin{array}{l}0,77 \\
3,21\end{array}$ & $\begin{array}{l}0,06 \\
0,28\end{array}$ & $\begin{array}{l}0,365 \\
0,168\end{array}$ & $\begin{array}{l}0,138 \\
0,121\end{array}$ & $\begin{array}{l}0,247 \\
0,905\end{array}$ & $\begin{array}{l}0,414 \\
0,368\end{array}$ \\
\hline $\begin{array}{l}\mathrm{G} / \mathrm{P} \\
F / P\end{array}$ & 1,13 & 1,11 & 1,15 & 1,10 & 1,08 & 0,06 & 0,363 & 0,543 & 0,703 & 0,325 \\
\hline $\begin{array}{l}\text { Efic. } \\
\text { Effic. }\end{array}$ & 0,20 & 0,20 & 0,22 & 0,23 & 0,22 & 0,01 & 0,004 & 0,606 & 0,202 & 0,815 \\
\hline
\end{tabular}

1 Porcentagem de inclusão do amido do milheto em relação ao amido do milho.

${ }^{1}$ Percentage of pearl millet stach added in relation to corn starch.

2 Probabilidade de haver efeito $(P): L=$ Linear; $Q=$ quadrático; $C=$ Cúbico; $Q t=$ quártico.

2 Probability of treatment effect: $L=$ linear; $Q=$ quadratic; $C=$ cubic; $Q t=$ quartic;

${ }^{3} \mathrm{CMS}=$ consumo de matéria seca; $\mathrm{PL}=$ =produção de leite; $\mathrm{PLC}=$ produção de leite corrigida para $3,5 \%$ de gordura; $\mathrm{G} / \mathrm{P}=$ gordura/proteína; Efic.=Eficiência de conversão da proteína consumida em proteína do leite (g proteína consumida/g proteína no leite).

${ }^{3} \mathrm{DMI}=$ dry matter intake; $M Y=$ milk yield; $M Y C F=$ milk yield correct for fat; $F / P=$ fat $/$ protein $;$ Effic. $=$ conversion

efficiency of protein intake in milk protein.

${ }^{4}$ Erro-padrão da média.

${ }^{4}$ Standard error of means.

observou-se efeito quártico $(\mathrm{P}<0,05)$ no teor de proteína, à medida que se aumentou a percentagem de milheto na dieta.

Gelaye et al. (1997) não encontraram diferença $(\mathrm{P}>0,25)$ na produção de leite e nos componentes do leite de cabras, ao substituírem o milho parcialmente $(50 \%)$ ou integralmente pelo milheto.

O teor de gordura no leite reflete o padrão de fermentação ruminal. Maior digestibilidade ruminal de amido poderia diminuir o $\mathrm{pH}$ ruminal, prejudicando a fermentação da fibra pelas bactérias celulolíticas, diminuindo a relação acetato/propionato. Essas alterações poderiam estar associadas à diminuição na síntese de gordura do leite. Como a substituição do amido do milho pelo amido do milheto não alterou o teor nem a produção de gordura no leite, supõe-se que a taxa de digestão ruminal do amido foi semelhante entre os grãos, dados suportados pelos valores de $\mathrm{pH}$ ruminal e concentração de ácido acético e propiônico (Tabela 6). Outro indicativo é que a relação gordura/ proteína (G/P) no leite entre os tratamentos não diferiu (Tabela 5).

Foi observado efeito quártico em relação à inclusão de milheto e o teor de proteína do leite (Tabela 5). Os tratamentos com 25 e $75 \%$ de amido do milheto proporcionaram os maiores valores $(3,08$ e $3,04 \%$, respectivamente), sendo o tratamento com $100 \%$ o que apresentou menor percentagem de proteína $(2,96 \%)$. Esse último tratamento possuiu menor teor de proteína proveniente do farelo de soja, considerado uma fonte protéica de boa qualidade em relação ao perfil de aminoácidos, quando comparada com a proteína do leite. O farelo de soja é adequado em lisina, mas deficiente em metionina (Schwab et al., 1976), enquanto o milho e milheto possuem maiores teores de metionina e são deficientes em lisina (Burton et al., 1972).

Quando se fez a substituição total do grão de milho pelo grão de milheto (100\%), o teor de lisina da dieta diminuiu, podendo ter alterado o teor de proteína 
do leite (Schwab, 1994; Santos \& Huber, 1996).

O efeito quártico resultante do ligeiro aumento de proteína no leite entre os tratamentos 50 e $75 \%$ (Figura 1). A equação obtida foi: $Y=-0,0000000041 X^{4}$ $+0,000008449 X^{3}+-0,00056924 X^{2}+0,0128533 X+$ 3,0027 , em que $\mathrm{Y}$ é igual à percentagem de proteína no leite e $\mathrm{X}$, à porcentagem de inclusão do amido de milheto em relação ao milho. Provavelmente, com maior número de repetições por tratamentos, os resultados poderiam ter refletido um platô de percentagem de proteína entre os tratamentos 50 e $75 \%$, seguido de queda brusca no tratamento $100 \%$.

Assim, a interpretação dos dados demonstra que o maior valor de percentagem de proteína do leite é atingido com $25 \%$ de inclusão de milheto. A partir daí, os valores diminuem até a total substituição do milho pelo milheto.

A síntese de proteína microbiana também influi no teor de proteína do leite. O perfil de aminoácidos dos microorganismos ruminais é de excelente qualidade. Dietas que aumentam a síntese de proteína microbiana, como uma fonte de amido mais digestível no rúmen, favoreceriam o aumento da concentração de proteína no leite. A sincronização da degradação ruminal de proteína e energia em vacas de alta produção é de extrema importância, objetivando-se maximizar a síntese de proteína microbiana e o fluxo de aminoácidos essenciais para o intestino (Santos \& Huber, 1996).
Não houve diferença $(\mathrm{P}>0,05)$ nos valores médios diários de $\mathrm{pH}$ entre os tratamentos (Tabela 6). As dietas continham $35 \%$ de amido na MS total, porém, em nenhum dos animais foi observado $\mathrm{pH}$ menor que 6 , evidenciando um ambiente ruminal adequado às bactérias. Esses dados estão de acordo com Terril et al. (1998), que trabalharam com bodes castrados alimentados com milho, milheto ou uma mistura de ambos (50:50). Hill \& Hanna (1990) também não observaram alteração no $\mathrm{pH}$ ruminal, ao avaliarem a

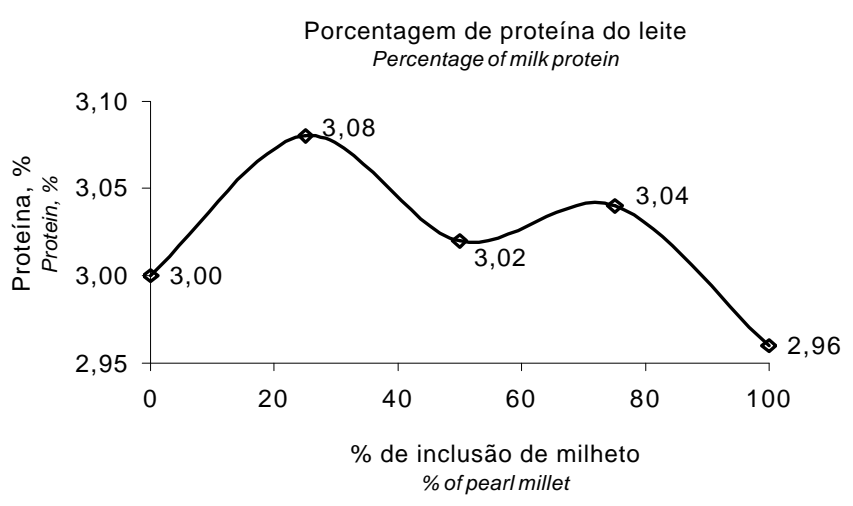

Figura 1 - Percentagem de proteína no leite com a inclusão de milheto.

Figure 1 - Percentage of milk protein as pearl millet increase.

Tabela 6 - Inclusão de milheto sobre os parâmetros ruminais

Table 6 - Pearl millet on ruminal parameters

\begin{tabular}{|c|c|c|c|c|c|c|c|c|c|c|}
\hline \multirow[t]{2}{*}{ Itens $^{3}$} & \multicolumn{5}{|c|}{$\begin{array}{c}\text { Tratamentos } \\
\text { Treatments }\end{array}$} & \multirow[b]{2}{*}{$\mathrm{EPM}^{4}$} & \multicolumn{4}{|c|}{$\begin{array}{c}\text { Efeito }^{2} \\
\text { Effect }\end{array}$} \\
\hline & $0 \%$ & $25 \%$ & $50 \%$ & $75 \%$ & $100 \%$ & & $\mathrm{~L}$ & $\mathrm{Q}$ & $\mathrm{C}$ & $\mathrm{Qt}$ \\
\hline $\mathrm{pH}$ & 6,38 & 6,38 & 6,38 & 6,41 & 6,33 & 0,03 & 0,371 & 0,635 & 0,237 & 0,517 \\
\hline $\mathrm{N}-\mathrm{NH}_{3}$ & 24,34 & 23,12 & 21,27 & 23,53 & 18,81 & 2,25 & 0,025 & 0,822 & 0,466 & 0,630 \\
\hline $\mathrm{AGV}^{3}$ & 137,6 & 134,2 & 134,0 & 137,8 & 135,7 & 4,65 & 0,848 & 0,410 & 0,555 & 0,808 \\
\hline$V F A$ & & & & & & & & & & \\
\hline $\mathrm{C}_{2}$ & 87,34 & 85,33 & 82,39 & 85,65 & 84,21 & 3,67 & 0,668 & 0,521 & 0,513 & 0,411 \\
\hline $\mathrm{C}_{3}$ & 29,35 & 27,37 & 30,58 & 30,50 & 30,12 & 3,70 & 0,453 & 0,877 & 0,445 & 0,644 \\
\hline $\mathrm{C}_{4}$ & 14,72 & 15,10 & 14,79 & 15,23 & 15,16 & 0,83 & 0,853 & 0,832 & 0,691 & 0,560 \\
\hline $\mathrm{C}_{2} / \mathrm{C}_{3}$ & 2,99 & 3,17 & 2,86 & 2,95 & 2,95 & 0,26 & 0,431 & 0,956 & 0,307 & 0,173 \\
\hline
\end{tabular}

1 Porcentagem de inclusão do amido do milheto em relação ao amido do milho.

1 Percentage of pearl millet stach added in relation to corn starch.

2 Probabilidade de haver efeito $(P): L=$ Linear; $Q=$ quadrático; $C=$ Cúbico; $Q t$ = quártico;.

2 Probability of treatment effect: $L=$ linear; $Q=q u a d r a t i c ; C=c u b i c ; Q t=$ quartic.

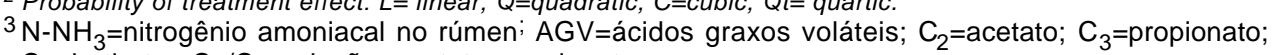
$\mathrm{C}_{4}=$ butirato; $\mathrm{C}_{2} / \mathrm{C}_{3}=$ relação acetato propionato.

${ }^{3} \mathrm{~N}^{-} \mathrm{NH}_{3}=$ Rumen ammonia nitrogen; VFA=volatile fatty acids; $C_{2}=$ acetate; $C_{3}=$ propionate; $C_{4}=$ butirate; $C_{2}$ ' $C_{3}=$ acetate propionate proportion.

${ }^{4}$ Erro-padrão da média.

${ }^{4}$ Standard error of mean.

\section{R. Bras. Zootec., v.33, n.5, p.1351-1359, 2004}


substituição do milho por milheto em novilhos, dados concordantes com os de Gelaye et al. (1997), que utilizaram cabras em lactação recebendo dietas com substituição do milho pelo milheto $(0,50$ e $100 \%$ de substituição). Entretanto, Hill et al. (1996) observaram diferenças no $\mathrm{pH}$ ruminal de novilhos, concluindo que as dietas com milho (menor $\mathrm{pH}$ ) foram fermentadas mais extensivamente que as dietas com milheto.

Observou-se relação inversa entre a concentração média diária de $\mathrm{N}^{-\mathrm{NH}_{3}}$ e a percentagem de inclusão de milheto na dieta (Tabela 6). Contudo, a interação entre tratamento e tempo não foi significativa $(\mathrm{P}>0,05)$.

$\mathrm{O}$ efeito linear na concentração de $\mathrm{N}-\mathrm{NH}_{3}$ pode ser atribuído ao mesmo efeito observado no consumo de nitrogênio (Tabela 4). Menores consumos de proteína foram relacionados com as menores concentrações de $\mathrm{N}-\mathrm{NH}_{3}$ no rúmen. Gelaye et al. (1997) observaram um declínio nos níveis de nitrogênio $(\mathrm{N})$ no fluido ruminal de cabras em lactação recebendo dietas em que o milho foi substituído pelo milheto $(0,50$ e $100 \%$ de substituição). O teor de ácido fítico de alguns grãos pode ser prejudicial à atividade de enzimas proteolíticas, diminuindo a digestibilidade da proteína e, conseqüentemente, do amido. Segundo Kumar \& Chauhan (1993), grãos de milheto não processados contêm considerável quantidade de ácido fítico (825,7 mg/100 g). Chauhan et al. (1986), citado por Kumar \& Chauhan (1993), observaram grande quantidade de ácido fítico no milheto e a digestibilidade da proteína e do amido nessas variedades foi relativamente baixa.

Não houve diferença $(P>0,05)$ na concentração média diária de AGV totais, acetato, propionato, butirato e na relação acetato/propionato entre os tratamentos (Tabela 6), nem na interação entre tratamento e tempo. Gelaye et al. (1997) também não observaram alterações na concentração de AGV no fluido ruminal de cabras em lactação alimentadas com dietas de milho e milheto. Os autores observaram aumento na concentração de acetato e diminuição na concentração de propionato, sendo que os tratamentos continham maiores teores de FDN, o principal responsável por um padrão de fermentação com maiores proporções de ácido acético. Dados semelhantes foram encontrados por Hill \& Hanna (1990) em relação a concentração de AGV. Contudo, esses autores observaram diminuição na concentração de acetato e aumento na concentração de propionato. Terril et al. (1998), trabalhando com bodes castrados, e Hill et al. (1996), utilizando novilhos, observaram diminuição na concentração de AGV no fluido ruminal, ao substituírem o milho por milheto, porém não observaram diferenças nos outros parâmetros ruminais.

Como o padrão de fermentação ruminal não foi alterado no presente trabalho, não era de se esperar diferença na relação acético/propiônico, o mesmo se verificando na porcentagem de gordura do leite $(\mathrm{P}<0,05)$, também um indicador dessa relação.O pH ruminal e ácido acético também sugerem que o comportamento da fermentação do amido dos grãos foram semelhantes.

Pode-se inferir que o amido de ambos os grãos têm comportamento similar em relação à susceptibilidade enzimática ruminal. Esses dados concordam com os de degradabilidade in situ dos grãos (Bruno et al., 1999), sugerindo pequena diferença na degradação ruminal do amido dos grãos de milho e milheto.

\section{Conclusões}

O grão de milheto é um bom substituto, total ou parcial, do grão de milho, em dietas de vacas produzindo $25 \mathrm{~kg} /$ dia de leite, sem alterar produção de leite e consumo dos animais.

\section{Agradecimento}

À FAPESP, pela concessão de bolsa e pelo financiamento do experimento.

\section{Literatura Citada}

ANDREWS, D.J.; KUMAR, K.A. Pearl millet for food, feed and forage. Advances in Agronomy, v.48, p.89-139, 1992. ASSOCIATION OF OFFICIAL ANALYTICAL CHEMISTS. Official methods of analysis. 12.ed. Washington: AOAC, 1990. $1117 \mathrm{p}$.

BRUNO, E.J.M.; RIBEIRO, C.V.D.M.; SIMAS, J.M.C. et al. Determinação da digestibilidade in situ de fontes de amido. In: SIMPÓSIO DE INICIAÇÃO CIENTÍFICA DA UNIVERSIDADE DE SÃO PAULO, 7., 1999, Piracicaba. Anais... São Paulo: SONOPRESS, 1999. CD-ROM. Agricultura. 3.51.

BURTON, G.W.; WALLACE, A.T.; RACHIE, K.O. Chemical composition and nutritive value of pearl millet [Pennisetum typhoides (Burm.) Stapf and E.C. Hubbard] grain. Crop Science, v.12, p.187-188, 1972.

CHANEY, A.L.; MARBACH, E.P. Modified reagents for determination of urea and ammonia. Clinical Chemistry, v. 8, p.130-137, 1962.

FANCHER, B.I.; JENSEN, L.S.; SMITH, R.L. et al. The metabolizable energy content of pearl millet [Pennisetum americanum (L.) Leeke]. Poultry Science, v.66, p.16931696, 1987.

GELAYE, S.; TERRILL, T.; AMOAH, E.A. et al. Nutritional 
value of pearl millet for lactating and growing goats. Journal of Animal Science, v.75, p.1409-1414, 1997.

HILL, G.M.; HANNA, W.W. Nutritive characteristics of pearl millet grain in beef cattle diets. Journal of Animal Science, v.68, p.2061-2066, 1990.

HILL, G.M.; NEWTON, G.L.; STREETER, M.N.; et al. Digestibility and utilization of pearl millet diets fed to finishing beef cattle. Journal of Animal Science, v.74, p.1728-1735, 1996.

HUNTINGTON, G.B. Ruminant starch utilization progress has been extensive. Feedstuffs, v.66, p.35, 1994.

HUNTINGTON, G.B. Starch utilization by ruminants: From basics to the bunk. Journal of Animal Science, v.75, p.852867, 1997.

JOY, M.T.; DePETERS, J.; FADEL, J.G. et al. Effects of corn processing on the site and extent of digestion in lactating cows. Journal of Dairy Science, v.80, p.2087-2097, 1997.

KUMAR, A.; CHAUHAN, B.M. Effects of phytic acid on protein digestibility (in vitro) and $\mathrm{HCl}$-extractability of minerals in pearl millet sprouts. Cereal Chemistry, v.70, p.504-506, 1993.

LANDRY, J.; DELHAYE, S. The tryptophan content of pearl millet grains as a function of nitrogen content. Phytochemistry, v.38, p.5-8, 1995.

NATIONAL RESEARCH COUNCIL - NRC. Nutrient requirements of dairy cattle. 6. ed. Washington, D.C.: National Academy of Science, 1988. 158p.

PERRI, S.H.V.; IEMMA, A.F. Procedimento "MIXED" do SAS para análise de modelos mistos. Scientia Agricola, v.56, p.959-967, 1999.
POORE, M.H.; ECK, T.P.; SWINGLE, R.S. et al. Total starch and relative starch availability of feed grains. In: BIENNIAL CONFERENCE ON RUMEN FUNCTION, 20., 1989, Chicago. Proceedings... Chicago: 1989. p.10.

SANTOS F.P.; HUBER J.P. Quality of bypass proteins fed to high-producing cows is important. Feedstuffs, v.68, p.12-15, 1996.

STATISTICAL ANALYSES SYSTEM - SAS. Users' guide: statistics. 5.ed. Cary: 1991.

SCHWAB, C.G.; SATTER L.D.; CLAY A.B. Response of lactating cows to abomasal infusion of amino acids. Journal of Dairy Science, v.59, p.1254-70, 1976.

SCHWAB, C.G. Optimizing amino acid nutrition for optimum yields of milk and milk protein. In: SOUTHWEST NUTRITION MANAGEMENT, Tucson, 1994. Proceedings... Tucson: 1994. p.114-129.

SUPLENCO INCORPORATION. GC separation of VFA $\mathbf{C}_{\mathbf{2}}$ C $_{5}$. Bulletin 749E, p.1-3, 1975.

TERRILL, T.H.; GELAYE, S.; AMOAH, E.A. et al. Protein and energy value of pearl millet grain for mature goats. Journal of Animal Science, v.76, p.1964-1969, 1998.

Van SOEST, P.J.; ROBERTSON J.B.; LEWIS B.A. Methods for dietary fiber, neutral detergent fiber, and nonstarch polysaccharides in relation to animal nutrition. Journal of Dairy Science, v.74, p.3583-3597, 1991.

Recebido em: 21/03/03

Aceito em: 24/11/03 